\title{
Spatial and Temporal Variations of Climatic Parameters under Changing Climate of Hindu Kush Himalayan Region of India
}

\author{
Rohitashw Kumar ${ }^{1 *}$ and Zeenat Farooq ${ }^{2}$ \\ ${ }^{1}$ Associate Professor, Sher-e-Kashmir University of Agricultural Sciences and Technology of Kashmir, India \\ ${ }^{2}$ Research Scholar, Sher-e-Kashmir University of Agricultural Sciences and Technology of Kashmir, India
}

Received: October 25, 2017; Published: October 30, 2017

*Corresponding author: Rohitashw Kumar, Division of Agricultural Engineering, Sher-e-Kashmir University of Agricultural Sciences and Technology of Kashmir, Shalimar campus, Srinagar, Jammu and Kashmir-190025, India; Email: rohituhf@rediffmail.com

\section{Mini Review}

Climate change can severely threat India's water security. India's hydro-climatic regime is expected to alter significantly over the course of the 21st century. If the current pattern of demand and usage continues, it is predicted that by 2030 about half the demand for water will be unmet. Growing population, rapid industrialization and urbanization, and climate change will further affect water availability. In this context, it is important for India to consolidate water resource management through rational estimates and regulation. The vulnerability of the Indian subcontinent to the impact of changing climate is of vital importance because the major impact of climate change in this continent would be on the hydrology, affecting water resources and agricultural economy. Water resource has become a prime concern for development and planning, including food production and flood control. The impact of climate change may be relatively severe with the reduction in the water availability over different parts of the globe. Hindu Kush Himalayan region of Jammu and Kashmir is a hill state having varied topography and great diversity in cultural, social and economic practices of its different regions.

However, agriculture remains the backbone of the economy of Jammu and Kashmir with over 65 percent of its population depends on agriculture and allied sectors. These sectors contribute around 27 percent to the State's income. The diversity in physiographic features, agro-climatic variations at macro and micro level, existence of cold arid, temperate, inter-mediate and sub-tropical zones. Over the years, the agriculturists and farmers have adopted several area specific and time specific cultivation practices to meet the requirement of their staple food crops. Dwindling water resources too is a major challenge as only 42 percent of the cultivated area is under irrigation. Fragile soil in hilly areas is susceptible to soil erosion and a single cropping season is available in temperate and high altitude areas. Net irrigated area in the region is just 24 percent Irrigation is an essential input of agriculture and is practiced in all parts of the world where rainfall does not provide enough ground moisture.

In areas of irregular rainfall, irrigation is used during dry spells to ensure harvests and to increase crop yields. A major constraint to the development of agriculture in Jammu and Kashmir is the fact that only 50 per cent of the ultimate irrigation potential of the state has been harnessed. The ultimate irrigation potential in Jammu and Kashmir has been assessed at 1358 thousand hectare, which includes 250 thousand hectare to be developed through major and medium irrigation and 1108 thousand hectare through minor irrigation. The impact of climate change on annual air temperature and precipitation and crop water requirement is great concern in present context. The present paper focused on detecting trends in maximum temperature, minimum temperature, precipitation, reference evapotranspiration, evaporation and relative humidity at monthly, seasonal and annual basis for different regions of $\mathrm{HKH}$.

Reference evapotranspiration (RET) plays a critical role in irrigation planning and is needed for the determination of water demands of crops. The widely used Mann-Kendall test was used at $5 \%$ and $10 \%$ significance level on time series data of 20 year (1995-2015) for Srinagar Kashmir region and 15 year data of Leh (2001-2015). The magnitude of the identified trends in the meteorological parameters was obtained through the parametric linear regression test. In order to identify the dominant variables among the independent variables associated with changes in dependent variable, a stepwise regression method was used. The results on monthly basis, annually and seasonal basis were carried out. In case of Srinagar on annual basis only RET (ET ) $_{\text {) witnessed }}$ statistically significant increasing trend at 5\% significance level.

Trend analysis on seasonal basis revealed that $\mathrm{ET}_{0}$ in autumn season at the rate of $8.32 \mathrm{~mm} /$ decade and in winter season at the rate of $8.63 \mathrm{~mm} /$ decade and precipitation in autumn season at 
the rate of $19.21 \mathrm{~mm} /$ decade witnessed statistically significant increasing trends only at $5 \%$ level of significance and no trends were observed in other seasons. No significant trends were witnessed in maximum temperature, minimum temperature, relative humidity and evaporation at $5 \%$ or $10 \%$ significance level. In case of Leh region, it is witnessed that statistically significant falling trends are witnessed in maximum temperature in the month of July at the rate of $1.70^{\circ} \mathrm{C} /$ decade, at $5 \%$ level of significance.

In case of minimum temperature statistically significant falling trend at $5 \%$ level of significance as the values of $\mathrm{Z}$ (Test Statistics) obtained through the MK test are more than -1.96 was witnessed in month of August at the rate of $1.31^{\circ} \mathrm{C} /$ decade. Statistically significant falling trend was witnessed in the month of December at the rate of $1.74^{\circ} \mathrm{C} /$ decade at $10 \%$ significance level. It is witnessed that statistically significant falling trends are witnessed in relative humidity in the month of March to December (at 5\% level of significance. On examining the results of stepwise regression to determine the meteorological parameters responsible for the observed $\mathrm{ET}_{0}$ changes, wind speed followed by sunshine duration, and temperature were found to be the main causative variables of the observed changes in the $\mathrm{ET}_{0}$ over Srinagar in the annual time scale.

It is understood that the global warming and its impact on the hydrological cycle and the nature of hydrological events would pose an additional threat to the Himalayan region. To harness this potential, India needs to invest soon in increasing storage capacity, improving water-use efficiency, and managing surface-water and groundwater resources in a sustainable way to avoid problems of soil Stalinization and water logging. In order to minimize the adverse impacts of climate change on country's water resources and attaining its sustainable development and management, there are needs of developing rational adaptation strategies. Thus, due consideration is required to be given to the effect of climate change while planning, designing and operation of the water resources projects.

These would be reflected in proper assessment of water resources, developing suitable hydrological design practices and operational policies for water projects, putting in place effective flood and drought management strategies, developing water efficient irrigation practices, etc. believes in a future in which the region's mountain people can experience enhanced livelihoods, equity, and social and environmental security in which they can adapt to environmental, socioeconomic, and climate change and in which generations of mountain and downstream populations can enjoy the benefits and opportunities afforded by the region's natural endowment.

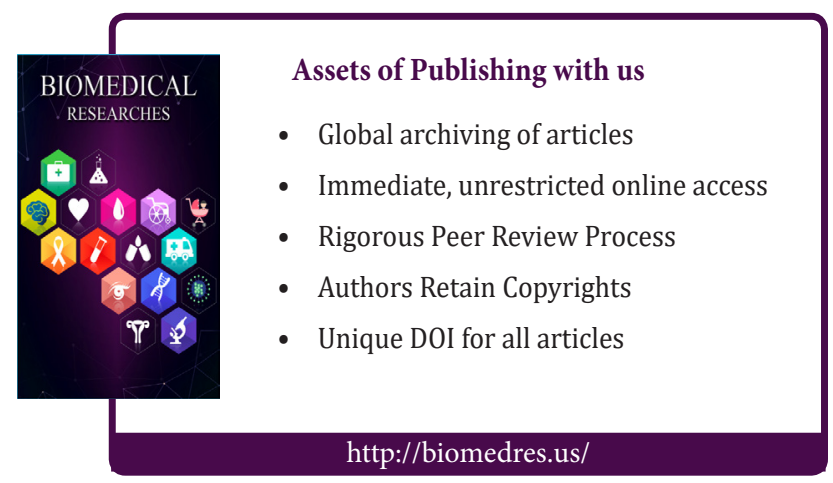

